This is the Accepted Manuscript of the article:

Díaz-Cintas, Jorge. 2018. "Audiovisual Translation in Mercurial Mediascapes", in Meng Ji and Michael Oakes (eds) Advances

in Empirical Translation Studies. Cambridge: Cambridge University Press.

www.cambridge.org/core/books/advances-in-empirical-translation-studies/3C13D7A2CD1B1F0BF80ADDF2C21C7D16

10

\title{
AUDIOVISUAL TRANSLATION IN MERCURIAL MEDIASCAPES
}

\author{
Jorge Díaz-Cintas \\ Professor of Translation Studies \\ Centre for Translation Studies, University College London, UK
}

\subsection{Introduction}

In the last decades, audiovisual translation (AVT) has been, without a doubt, one the most prolific areas of research in the field of translation and interpreting studies, if not the most prolific. For many years ignored in academic circles, AVT has existed as a professional practice since the invention of cinema, though it was not until the mid-1990s, with the advent of digitisation, that it began to gain in scholarly prominence and in number of acolytes. The flurry of activity observed in the media and the technology industries has had a positive knock-on effect on the raising of the visibility and status of AVT at academic level too, as attested by the exponential growth in the number of publications, conferences, research projects as well as undergraduate and postgraduate courses that have been developed around the world in a relatively short period of time.

In a technologically driven multimedia society like the present one, the value of moving images, accompanied with sound and text, is crucial when it comes to engaging in communication. We live our working and personal lives surrounded by screens of all shapes and sizes: television sets, cinema screens, desktop computers, laptops, video game consoles, and mobile phones are a common and recurrent feature of our socio-cultural environment, heavily based on the omnipresence of the image. Entanglements with technology punctuate our daily routine as we experience a great deal of exposure to screens and consume vast amounts of audiovisual programmes to enjoy ourselves, to obtain information, to carry out our work, to learn and study, and to develop and enhance our professional and academic careers. Moving images are ubiquitous in our time and age and their power and influence are here to stay and live on via the screens.

This tallies well with the constant linear increase that has been observed in the use of computers and digital devices, particularly among the younger generations (Ferri 2012). In his discussion on the new divide between 'digital natives' and 'digital immigrants', the latter aka 'Gutenberg natives', Prensky (2001: 1) argues that today's students, making special reference to graduates in the USA:

have spent their entire lives surrounded by and using computers, videogames, digital music players, video cams, cell phones, and all the other toys and tools of the digital age. Today's average college grads have spent fewer than 5,000 hours of their lives reading, but over 10,000 hours playing video games (not to mention 20,000 hours watching TV). Computer games, e-mail, the Internet, cell phones and instant messaging are integral parts of their lives.

Along the same lines, but in the case of the UK, Elks (2012: online) highlights that 'children will spend an entire year sat in front of screens by the time they reach seven', with an average of 6.1 hours a day spent on a computer or watching TV and with 'some ten and 11-year-olds having access to five screens at home'. In the battle between paper and the digital page, it is the latter that seems to be winning, which coupled with the affordances of technology and the pervasiveness of the Internet, means that audiovisual communication is now a daily occurrence for millions of netizens around the globe. 
This is the Accepted Manuscript of the article:

Díaz-Cintas, Jorge. 2018. "Audiovisual Translation in Mercurial Mediascapes", in Meng Ji and Michael Oakes (eds) Advances in Empirical Translation Studies. Cambridge: Cambridge University Press.

www.cambridge.org/core/books/advances-in-empirical-translation-studies/3C13D7A2CD1B1F0BF80ADDF2C21C7D16

All forms of communication are based on the production, transmission and reception of a message amongst various participants. Though, on the surface, this seems to be a rather straightforward process, human interaction of this nature can be complex even when the participants share the same language, and more so when they belong to different linguacultural communities. That is why practices like translation have existed for centuries, to facilitate communication and understanding amongst cultures, as well as to promote networks of power and servitude. To a large extent, translation can be said to be running parallel to the history of communication and has experienced a similar transition in recent decades from the printed page to the more dynamic, digital screen. From this perspective, and given the exponential growth experienced by audiovisual communication, the boom witnessed in the industry's increased volume of audiovisual translation comes as no surprise. Technological advancements have had a great impact on the way we deal with the translation and distribution of audiovisual productions, and the switchover from analogue to digital technology at the turn of the last millennium proved to be particularly pivotal and a harbinger of things to come. Known as the fourth industrial revolution (Schwab, 2016), we are in the midst of a technical transformation that is fundamentally changing the way in which we live, work and relate to one another. In an age defined by technification, digitisation and internetisation, the world seems to have shrunk, contact across languages and cultures has accelerated and exchanges have become fast and immediate. Symbolically, VHS tapes have long gone, the DVD and VCD came and went in what felt like a blink of an eye, Blu-rays never quite made it as a household phenomenon, 3D seems to have stalled and, in the age of the cloud, we have become consumers of streaming, where the possession of actual physical items is a thing of the past.

The societal influence of AVT has expanded its remit in terms of the number of people that it reaches, the way in which we consume audiovisual productions and the nature of the programmes that get to be translated. If audiovisual translation came first to be as a commercial practice to enhance the international reach of feature films, the situation has changed quite drastically and the gamut of audiovisual genres that get translated nowadays is virtually limitless, whether for commercial, ludic or instructional purposes: films, TV series, cartoons, sports programmes, reality shows, documentaries, cookery programmes, current affairs, edutainment material, commercials, educational lectures and corporate videos to name but a few. The digital revolution has also had an impact on the very essence of newspapers, which have migrated to the web and now host videos on their digital versions that are usually translated with subtitles when language transfer is required. Consumption of audiovisual productions has also been altered significantly, from the large public spaces represented by cinema, to the segregated family experience of watching television in the privacy of the living room, to the more individualistic approach of binge watching in front of our personal computer, tablet or mobile telephone. The old, neat distinction between the roles of producers and consumers has now morphed into the figure of the prosumer, a direct result of the new potentiality offered by social media and the digital world. In addition to watching, consuming and sharing others' programmes, netizens are also encouraged to become producers and create their own user-generated content that can be easily assembled with freely available software programs and apps on their computers, smartphones or tablets, uploaded to any of the numerous sharing platforms that populate the ether and distributed throughout the world in an instantaneous manner.

As foregrounded by Shetty (2016, online), digital video has been in hyper growth mode over the last few years, "with a projected $80 \%$ of all Internet traffic expected to be video by 2018. This is because of improvements in video technology, wider viewing device options, and an increase in content made available online both from television broadcasters and from other video services.' Simultaneously, giants like YouTube estimate that more than 60 per cent of a 
This is the Accepted Manuscript of the article:

Díaz-Cintas, Jorge. 2018. "Audiovisual Translation in Mercurial Mediascapes", in Meng Ji and Michael Oakes (eds) Advances in Empirical Translation Studies. Cambridge: Cambridge University Press.

www.cambridge.org/core/books/advances-in-empirical-translation-studies/3C13D7A2CD1B1F0BF80ADDF2C21C7D16

YouTube channel's views come from outside its country of origin (Reuters, 2015), clearly pointing to the pivotal role of translation in cross-cultural communication. The parallel commercial upsurge of translation activity in the audiovisual industry has been corroborated by research conducted on behalf of the Media \& Entertainment Services Alliance Europe, underlining that audiovisual media content localisation across Europe, the Middle East and Africa is expected to increase from $\$ 2$ billion in 2017 to over $\$ 2.5$ billion before 2020 (MESA News, 2017). The mushrooming of channels and video on-demand platforms, driven partly by so-called over-the-top (OTT) players like Netflix, Amazon Prime, Viki, Hulu, iQiyi or Iflix to name but a few, who specialise in the delivery of content over the Internet, has opened up more opportunities for programme makers to sell their titles into new markets. To be successful in this venture, most audiovisual productions come accompanied by subtitled and dubbed versions in various languages, with many also including subtitles for the deaf and the hard of hearing (SDH) and audio description (AD) for the blind and the partially sighted. Never before has translation been so prominent on screen.

A collateral result from this fast-growing global demand for content that needs to be translated - from high-profile new releases to back-catalogue TV series and films for new audiences in regions where they have not been commercialised previously, without forgetting the myriad of new genres that a few years back would not have been translated - is the perceived critical 'talent crunch' (Estopace, 2017) in the industry, when it comes to dubbing and subtitling. Given the lack of formal AVT training in many countries, the situation is likely to get worse in the short term, especially in the case of certain language combinations.

Yet, what is certain is that the demand for audiovisual translation is here to stay, as companies and organisations around the world continue to recognise the immense value of adapting their content into multiple languages to extend their global reach. Its playbook, however, is still an evolving paradigm.

\subsection{The Multimodality of Audiovisual Translation}

In her attempt to dispel inherited assumptions that have had the pernicious effect of academically marginalising certain translational practices, O'Sullivan (2013: 2) remarks that ' $\mathrm{t}$ ]ranslation is usually thought of as being about the printed word, but in today's multimodal environment translators must take account of other signifying elements too'; a warning also echoed by Pérez-González (2014: 185), who bemoans the excessive emphasis placed by AVT researchers on the linguistic analysis of often decontextualised dialogue lines, and for whom the need 'to gain a better understanding of the interdependence of semiotic resources in audiovisual texts has become increasingly necessary against a background of accelerating changes in audiovisual textualities'. In this respect, greater scholarly attention to the interplay between dialogue and the rest of semiotic layers that configure the audiovisual production can only be a positive, if challenging, development for the discipline.

One of the early scholars to discuss the significance for translation of the multimodal nature of the source text is Reiss (2000/1971), who in her text typology for translators distinguishes three initial groups, namely (1) content-focused texts, (2) form-focused texts and (3) appeal-focused texts. To these, she adds a fourth, overarching category that she refers to as audio-medial texts and, in her own words, 'are distinctive in their dependence on non-linguistic (technical) media and on graphic, acoustic, and visual kinds of expression. It is only in combination with them that the whole complex literary form realizes its full potential' (ibid., 43). Primary examples of this category are texts that require 'the use of and a degree of accommodation to a non-linguistic medium in order to communicate with the hearer' (ibid.), as in radio and television scripts, songs, musicals, operas and stage plays. Audio-medial texts 
This is the Accepted Manuscript of the article:

Díaz-Cintas, Jorge. 2018. "Audiovisual Translation in Mercurial Mediascapes", in Meng Ji and Michael Oakes (eds) Advances in Empirical Translation Studies. Cambridge: Cambridge University Press.

www.cambridge.org/core/books/advances-in-empirical-translation-studies/3C13D7A2CD1B1F0BF80ADDF2C21C7D16

seem then to be aimed at hearers, since they 'are written to be spoken (or sung) and hence are not read by their audience but heard' (ibid., 27). From the perspective of AVT, the term is clearly problematic and Reiss's taxonomy is also rather wanting as any reference to the main film translation modes, whether dubbing or subtitling, is conspicuously absent in her work and the emphasis is placed, symptomatically, on the 'hearer' rather than the 'viewer/reader'. In fact, the only mention of dubbing is hidden away in a footnote, where she quotes directly from Jumpelt $(1961,24)$ - 'in the setting of filming dialog the critical factor may well be the necessity for finding expressions that effectively carry the meaning and match most closely the actors' lip movements' - and refers the reader to the pioneering 1960 special issue of the journal Babel, entitled Cinéma et Traduction and guest-edited by Pierre-François Caillé (Reiss, 2000/1971, 46).

A decade later, she revisited the term and changed it to 'multi-medial', after acknowledging the fact that:

the translating material does not only consist of "autonomous" written texts, but also, to a large extent, firstly of verbal texts, which, though put down in writing, are presented orally, and, secondly, of verbal texts, which are only part of a larger whole and are phrased with a view to, and in consideration of, the "additional information" supplied by a sign system other than that of language (picture + text, music and text, gestures, facial expressions, built-up scenery on the stage, slides and text, etc.) (Reiss 1981: 125).

In effect, this hypertext continues to function as a super-structure for the three basic types and allows her to include texts like comics and advertising material, which resort to visual but not acoustic elements. In an attempt to overcome the limitations of Reiss's terminological framework of reference and to dispel any potential confusion, Snell-Hornby (2006: 85) defines four different terms for four different classes of text that all depend on elements other than the verbal:

1. Multimedial texts (in English usually audiovisual) are conveyed by technical and/or electronic media involving both sight and sound (e.g. material for film or television, sub-/surtitling),

2. Multimodal texts involve different modes of verbal and nonverbal expression, comprising both sight and sound, as in drama and opera,

3. Multisemiotic texts use different graphic sign systems, verbal and non-verbal (e.g. comics or print advertisements),

4. Audiomedial texts are those written to be spoken, hence reach their ultimate recipient by means of the human voice and not from the printed page (e.g. political speeches, academic papers).

In all cases, we are dealing with texts that go beyond language and that in Translation Studies 'until well into the 1980 s were hardly investigated as a specific challenge for translation' (ibid.).

Delabastita (1989) is one of the first scholars to elaborate further this multimodal dimension that so characterises what he calls 'film and TV translation' and that rests on the intricate combination of the acoustic and the visual channels, which together with the verbal and the nonverbal dimensions of communication, results in the four basic elements that define the audiovisual text and validate its semiotic texture:

1. The acoustic-verbal: dialogue exchanges, monologue, lyrics, voice-off.

2. The acoustic-non-verbal: instrumental music, sound effects, laughter, crying, background noises.

3. The visual-verbal: street signs, banners, opening/closing credits, text on screen, letters, messages on computer screens, newspapers headlines.

4. The visual-non-verbal: images, lighting, gestures, facial expressions. 
This is the Accepted Manuscript of the article:

Díaz-Cintas, Jorge. 2018. "Audiovisual Translation in Mercurial Mediascapes", in Meng Ji and Michael Oakes (eds) Advances in Empirical Translation Studies. Cambridge: Cambridge University Press.

www.cambridge.org/core/books/advances-in-empirical-translation-studies/3C13D7A2CD1B1F0BF80ADDF2C21C7D16

The interdependence that exists among these various meaning-making resources has been theorised by Baldry and Thibault (2006) and their resource integration principle, which refers to the way in which multiple semiotic layers co-exist in the same multimodal text and affect each other in various ways. They argue that multimodal texts do not function as a mere juxtaposition of resources and assert that meaning is ultimately created through the interrelations of modes within a given text. The ensuing meaning is thus the result of the highly complex relationships that get established among the various semiotic elements and that cannot be expressed as a sum of meanings individually conveyed by each of the resources. When confronted with this vast array of communicative layers and signs, and as foregrounded by Pérez-González (2014: 188), viewers 'are normally able to make inter-modal connections and process the information realized through different modes in a routinized, often subconscious, manner'.

Although, a priori, all dimensions can be thought to play an equally important role within the communicative encounter, their degree of interdependence will vary depending on the genre and nature of the audiovisual production as well as the intended audience. Thus, the visual-non-verbal dimension, i.e. the image, might carry more weight than the word in the case of some of the big blockbuster films touring the world, whereas the acoustic-verbal, i.e. the spoken word, will be more prevalent in certain films d'auteur and documentaries. Naturally, this imbalance can also be found at different points within the same audiovisual programme, where some scenes may be of a verbose nature, whilst others will rely on special effects to the detriment of dialogue. From a translational perspective, such interplay amongst the various semiotic resources can on occasions be decisive when deciding on the preferred approach to activate for the language transfer. From a scholarly angle, it is this enmeshment and communicative richness inherent to multimodality that makes audiovisual productions so arresting to produce and to consume as well as to interpret and to investigate.

\subsection{The Many Instantiations of Audiovisual Translation}

Used as an umbrella term, AVT subsumes a raft of translation practices that differ from each other in the nature of their linguistic output and the translation strategies on which they rely. In addition to having to deal with the communicative complexities derived from the concurrent delivery of aural and visual input, audiovisual translators have to be conversant with the spatial and temporal constraints that characterise this translation activity as well as with the specialised software that is used in this profession. The various ways in which audiovisual productions can be translated into other languages have been discussed by many authors over the years, of which the typology presented by Chaume (2013) is perhaps one of the most recent and complete. What follows is a panoptic overview of each of the main modes.

Two fundamental approaches can be distinguished: either the source text oral output is transferred aurally in the target language (i.e. re-voicing) or is converted into written text that appears on screen (titling, text localisation). Within these two all-encompassing approaches, further sub-categorisations can be established. Thus, re-voicing subsumes interpreting, voiceover, narration, dubbing, fandubbing and audio description.

In simultaneous interpreting, the source speech is transferred by an interpreter, who listens to the original and verbally translates the content. Voiceover consists in orally presenting the translation of the source text speech over the still audible original voice, usually allowing the speaker to be heard for a few seconds in the foreign language, after which the volume of the soundtrack is reduced and the translation is then overlaid. In the case of narration, the original speech is obliterated and replaced by a new soundtrack containing only the voice of the target language narrator. Dubbing, also known as lip-sync, consists in the substitution of 
This is the Accepted Manuscript of the article:

Díaz-Cintas, Jorge. 2018. "Audiovisual Translation in Mercurial Mediascapes", in Meng Ji and Michael Oakes (eds) Advances in Empirical Translation Studies. Cambridge: Cambridge University Press.

www.cambridge.org/core/books/advances-in-empirical-translation-studies/3C13D7A2CD1B1F0BF80ADDF2C21C7D16

the dialogue track of an audiovisual production with another track containing the new lines in the target language. To make viewers believe that the characters on screen share the same language, three types of synchronisation need to be respected: (1) lip synchrony, to ensure that the translated sounds fit into the mouth of the onscreen characters, (2) isochrony, to guarantee that the duration of the source and the target utterances coincide in length, especially when the characters' movements of the mouth can be seen, and (3) kinetic synchrony, to assure that the translated dialogue does not contradict the thespian performance of the actors. Fandubbing refers to the dubbing or redubbing, done by fans, of audiovisual productions that have not been officially dubbed or whose available dubbed versions are deemed to be of poor quality. Mostly interlingual, some of them are also intralingual, in which case the intent is primarily humorous and they are known as 'fundubs'. Finally, audio description converts images and sounds into text by describing any visual or audio information that will help visual impaired audiences to follow the plot of the story, such as body language and facial expressions, scenery, costumes and the like.

The second main approach to AVT, titling, comprises subtitling, fansubbing, surtitling, subtitling for the deaf and the hard of hearing and respeaking. Subtitling is the rendition in writing of the translation of the original dialogue exchanged amongst the various speakers, as well as of all other verbal information that is transmitted visually (letters, banners, inserts) or aurally (lyrics, voices-off). Subtitles are usually confined to a maximum of two lines, each containing some 39 to 42 characters and displayed at the bottom of the screen. They appear in synchrony with the dialogue and the image and remain visible for between one and six seconds (Díaz-Cintas and Remael, 2007). Technically similar to subtitling, though still exhibiting some remarkable differences in terms of layout and activated translation strategies, fansubbing designates the subtitling carried out on the Internet by fans and amateurs. Surtitling, or supertitling, refers to the translation or transcription of dialogue and lyrics in live opera, musical shows and theatre performances, which is then displayed on a screen located above the stage or placed in the seat in front of the patron. As an assistive service, subtitling for the deaf and the hard of hearing, aka captioning, presents on screen a written text that accounts for the dialogue and its paralinguistic dimension as well as for music, sounds and noises contained in the soundtrack so that audiences with hearing impairments can access audiovisual material. Respeaking is the production of subtitles for live programmes or events, whereby a professional listens to the original utterances and repeats them, including punctuation marks, to a speechrecognition software that then displays the text on screen.

For some, AVT fell short of being a case of translation proper because of the various spatial and temporal limitations that constrain the end result, a conceptualisation that for many years stymied the academic development of this discipline. Today, translation has evolved from a corseted, outdated notion of a term coined many centuries ago - when the cinema, the television, the computer and Internet had not yet been invented - into a more flexible and inclusive concept that accommodates new professional practices and realities. In this evolution, AVT has come to question and reframe long-established tenets such as text, authorship, original work, translation unit or fidelity to the original.

Yet, when it comes to investigating the different professional practices, the general approach has been to study them together under the umbrella term of audiovisual translation, even though their study would gain in depth and substance if approached individually. Although some commonalities can be certainly discerned, the differences that separate them warrant more targeted analyses. For instance, the challenges raised by the shift from speech to written text are typically encountered in subtitling but not in dubbing; the transfer of discourse markers, exclamations and interjections plays a crucial role in the perceived naturalness of the dubbed exchanges but not so much in subtitling; the nature and recurrence of the translation 
This is the Accepted Manuscript of the article:

Díaz-Cintas, Jorge. 2018. "Audiovisual Translation in Mercurial Mediascapes", in Meng Ji and Michael Oakes (eds) Advances in Empirical Translation Studies. Cambridge: Cambridge University Press.

www.cambridge.org/core/books/advances-in-empirical-translation-studies/3C13D7A2CD1B1F0BF80ADDF2C21C7D16

strategies activated in dubbing and subtitling vary greatly and whilst condensation and deletion can be considered pivotal to subtitling, they are not so pervasive in dubbing; the ineffability of linguistic variation in written subtitles can be easily overcome by dubbing actors' voice inflection; and the cohabitation of source and target languages in the subtitled version straightjackets potential translation solutions in a way that does not happen in dubbing.

\subsection{Research Hotspots in Audiovisual Translation}

The sprouting media interest in AVT can also be tracked in academia, where a vast number of publications and doctoral projects have seen the light in the last two decades. However, as foregrounded by Gambier and Ramos Pinto (2016: 185), this exponential growth 'does not negate the fact that it is still a very young domain of research currently exploring an incredible number of different lines of inquiry without a specific methodological and theoretical framework', which means that any attempt to provide a comprehensive overview of the main developments taking place in such a vibrant area is bound to be partial.

If empiricism is to be broadly understood as an approach to knowledge that is based on observation and experience rather than on conjecture and abstract theorisation, then research in AVT can be said to have been firmly rooted in empirical endeavours since its humble beginnings in the second half of the twentieth century. Many of the early studies conducted in this field are of a descriptive nature and concentrate on the translation product - i.e. the actual translation - rather than on the process. As can be expected, the object of research in these pioneering scholarly publications, by antonomasia, was the film, which in more recent times has diversified to encompass other genres, notably TV series and animation, and, to a lesser extent, documentaries.

As already mentioned, a common drawback observed in some publications on the topic is reflected in the fact that they do not seem to take proper account of the semiotic dimension and, when discussing the translation solutions, tend to focus on the linguistic aspects and the translational strategies activated by the translators, at the expense of the images and the sound. Mirroring other types of translation, the scholarly exploration of AVT has been typically partisan to examinations centred on linguistics and discourse analysis; arguably a direct consequence of a research tradition that, in the case of translation, has been clearly literary, printed-text oriented and has drawn its inspiration largely from comparative linguistics. Notwithstanding the potential limitations, it is also true that their results have decisively contributed to the painting of a more rounded picture of the discipline by addressing its practical needs. With the passing of the years, the scope of the research has widened considerably to encompass many other aspects that directly impinge on the interlingual transfer that takes place. This has enabled the profusion of works in which particular emphasis has been placed on the challenges presented by the transfer of humour (Zabalbeascoa, 1996; MartínezSierra, 2008), cultural references (Ramière, 2007; Pedersen, 2011; Ranzato, 2016) and, more recently, taboo language (Ávila Cabrera, 2014; Yuan, 2016) and multilingualism (de Higes Andino, 2014; Beseghi, 2017).

The trope of translation as a bridge that enables understanding between cultures and communities requires urgent revision as it has been proven once and again that it can also stress differences and perpetuate negative stereotypes, hence dynamiting those very bridges it is supposed to build. The act of translating is never neutral and AVT scholars are awakening to the reality that mass media is an extraordinarily powerful tool, not only in the original but also in their translation. This heightened awareness of the power of translation has led to the realisation that commercial and political dominance, rather than linguistic asymmetries between languages, are often catalysts in the way cultural values are transferred in interlingual 
This is the Accepted Manuscript of the article:

Díaz-Cintas, Jorge. 2018. "Audiovisual Translation in Mercurial Mediascapes", in Meng Ji and Michael Oakes (eds) Advances in Empirical Translation Studies. Cambridge: Cambridge University Press.

www.cambridge.org/core/books/advances-in-empirical-translation-studies/3C13D7A2CD1B1F0BF80ADDF2C21C7D16

exchanges. Translation has come a long way to be understood as a form of rewriting (Lefevere 1992), i.e. a discursive activity embedded within a system of conventions and a network of institutions and social agents that, acting as gatekeepers of a given ideology, condition textual production and activate manipulation, to varying degrees, of the original text in the service of the powers that be. Since no translation can ever be the same as the original, unavoidable departures from the original will happen to a greater or lesser extent. In academic exchanges, the term manipulation is closely linked to censorship though a distinction can be established, in the specific field of AVT, between technical manipulation, prompted by space and time limitations imposed by the medium, and ideological manipulation or censorship, which, irrespective of the technical constraints, unscrupulously misconstrues what is being said (or shown) in the original and is usually instigated by agents in a position of power, who act according to a certain political agenda (Díaz-Cintas 2012). Given the vastness of the topic, any scholarly approach will benefit from charting it on the basis of different national, historical and socio-political environments. Historical accounts of how censorial forces have expurgated political, ethnic, religious, moral and sexual references in audiovisual materials, particularly from the perspective of dubbing, have been conducted by authors like Pruys (1997) in Germany, Mereu Keating (2016) in Italy, and Díaz-Cintas (2019), Gutiérrez Lanza (2002) and Vandaele (2002) in Spain.

Case studies are a convenient, easy-to-articulate research method that can help collect data and shed light on different contexts and domains by closing in on a given subject matter. As a regular feature in AVT scholarship, they tend to focus on small bodies of work, raising issues about their limited scope of action and the difficulty of generalising and extrapolating any of their findings. To counteract some of these shortcomings, scholars have approached AVT from other angles, taking inspiration from paradigms that allow the analysis of larger data, such as corpus linguistics. In this respect, corpora and corpus-analysis tools have been successfully used to systematically identify the idiosyncratic, recurrent features and patterns of larger sets of translated audiovisual productions across time, genres and languages (Freddi and Pavesi, 2009; Baños, Bruti and Zanotti, 2013). As already discussed, the multimodality of audiovisual texts demands that any study considers not only the dialogue but also the visual and the acoustic-non-verbal components. So, whilst this methodology has proven successful in the exploration of language, the design and construction of corpora that also include video material is not without its challenges as tagging the clips is a rather onerous task and securing permission to use and share them can prove most elusory. These are some of the reasons why corpus-based AVT studies tend to draw on relatively small corpora, as having a controllable amount of data allows for a quantitative and qualitative analysis that takes into consideration not only information transmitted through codes other than the linguistic one, but also permits the researcher to reflect on the many other factors that might have influenced certain solutions: synchrony between subtitles and soundtrack, respect of shot changes, semiotic cohesion, and adherence to spatial and temporal constraints, to name but a few.

Social inclusion in the form of accessibility to audiovisual media for people with sensory impairments has become an important issue in many countries around the globe, featuring prominently in legislation, academic exchanges and broadcasters' output. As government regulators impose new rules and regulations on broadcasters and other distributors regarding access services to audiovisual media, the various stakeholders in the field are joining efforts to conduct empirical research that can inform the professional world. Its novelty and alluring nature have triggered a great deal of interest in a relatively short period of time, emphasising its role as a tool for social integration and proving its versatility when it comes to the application of different inquiring methodologies, like Action Research in the case of subtitling for the deaf and the hard of hearing (Neves, 2005) and Actor Network Theory in the 
This is the Accepted Manuscript of the article:

Díaz-Cintas, Jorge. 2018. "Audiovisual Translation in Mercurial Mediascapes", in Meng Ji and Michael Oakes (eds) Advances in Empirical Translation Studies. Cambridge: Cambridge University Press.

www.cambridge.org/core/books/advances-in-empirical-translation-studies/3C13D7A2CD1B1F0BF80ADDF2C21C7D16

study of audio description (Weaver, 2014). The lobbying of interest groups has been instrumental in bringing about changes in this field, which has evolved fast in some countries but is still in its infancy in many other parts of the world. Pioneering research in this field has also proven instrumental in the professional development of access services that have taken off in some countries thanks to the championing of scholars, as in the case of SDH in the UK (Baker, Lambourne and Rowston, 1984) and in Portugal (Neves, 2005), and that of AD in Hong Kong (Leung, 2015).

In addition to the works that explore the specific nature of the various access services like SDH (de Linde and Kay 1999, Neves 2005) and AD (Fryer 2016, Vercauteren 2016) many other studies focus on end-reception with the aim of identifying the likes and dislikes of the audience and improving access to audiovisual productions, such as the projects by Zárate (2014) and Tamayo-Masero (2015) on children's reception of SDH, and the work by RomeroFresco (2011) on subtitling through speech recognition. As for AD, interest has also been placed on reception issues (Maszerowska, Matamala and Orero, 2014) as well as on the drafting of pan-European protocols and the training of professional AD specialists (ADLAB-Pro project, https://adlabpro.wordpress.com). The EU-funded project Digital Television for All (DTV4All, www.psp-dtv4all.org) and its follow-up, Hybrid Broadcast Broadband for ALL (HBB4ALL, http://pagines.uab.cat/hbb4all), have both taken a technological slant and focused on fostering and facilitating the provision of access services on digital television. RomeroFresco's (2013) notion of accessible filmmaking, as a potential way to integrate AVT and accessibility during the filmmaking process through collaboration between filmmakers and translators, is a brave attempt to exploit synergies, cement links and narrow the breach between translation studies and film and television studies.

To a very large extent, AVT has been at the mercy of the twists and turns of technology, which has had a considerable impact in our field, visible in the way professional practice has changed, the profile of translators and other professionals has evolved, and existing forms of AVT have adapted and developed into new hybrid ones. It is thanks to the instrumental role played by technology that subtitles can today be perfectly synchronised and produced live with minimal latency; that subtitlers' productivity has been boosted with the manufacturing of userfriendly software; and that new workflows, like crowdsubtitling, have emerged under the shelter of the cloud.

The role played by technology has been crucial not only with regard to the way AVT professional practices have evolved but also to the manner in which research has responded to these changes. The difficulty of getting hold of the actual physical material, together with the tedium of having to transcribe the dialogue and translations, and having to wind and rewind the video tape containing them, may help partly justify the reluctance to conduct research on AVT before the 1990s. Against this backdrop, the advent of digital technology can be hailed as an inflection point for the industry and the academe. A new distribution format, the DVD, acted as a research accelerator as it facilitated access to multiple language versions of the same production on the same copy (Kayahara 2005) and allowed the easy extraction (ripping) of the subtitles and the timecodes. Conducting now comparative analyses across languages, or getting hold of a seemingly infinite number of audiovisual programmes with their translations, had become a walk in the park. It is not surprising, therefore, that the number of scholarly publications started to grow exponentially around this time, which coincided with the then upcoming Descriptive Translation Studies paradigm postulated by Toury (1995), thus explaining why a large number of projects carried out in the field subscribed to this theoretical framework. The industry had come up with a novel way of distributing audiovisual material that not only had captivated the audience, but it had also revolutionised the way in which translations were produced, distributed, consumed and studied. The more recent introduction 
This is the Accepted Manuscript of the article:

Díaz-Cintas, Jorge. 2018. "Audiovisual Translation in Mercurial Mediascapes", in Meng Ji and Michael Oakes (eds) Advances in Empirical Translation Studies. Cambridge: Cambridge University Press.

www.cambridge.org/core/books/advances-in-empirical-translation-studies/3C13D7A2CD1B1F0BF80ADDF2C21C7D16

of streaming continues to put the consumer firmly in the driver's seat, with the offering of productions that have been translated into several languages and are available in dubbed and subtitled versions, though obtaining the material for research purposes may not be as straightforward as before.

An area of great interest to the industry has been the application of computer-assisted translation (CAT) tools and machine translation to increase productivity and cope with high volumes of work and pressing deadlines (Bywood, Georgakopoulou and Etchegoyhen, 2017). Whilst in regular use in the more traditional localisation industry, these have not seen a significant uptake in the AVT arena. Yet, the relative ease with which quality subtitle parallel data can be procured has been the catalyst for the recent uptake in experimentation in subtitling with statistical machine translation (SMT). Under the aegis of the European Commission, projects like SUMAT (SUbtitling by MAchine Translation, 2011-2014) have focused on building large corpora of aligned subtitles in order to train SMT engines in various language pairs. Its ultimate objective is to automatically produce subtitles, followed by human postediting, in order to increase the productivity of subtitle translation procedures, and reduce costs and turnaround times whilst keeping a watchful eye on the quality of the translation results. A similar project, conducted also around the same time, 2012-2014, was EU-BRIDGE (www.eubridge.eu), whose main goal was to test the potential of speech recognition for the automatic subtitling of videos.

As highlighted by Jenkins (2006, 17-18), 'new media technologies have lowered production and distribution costs, expanded the range of available delivery channels, and enabled consumers to archive, annotate, appropriate, and recirculate media content in powerful new ways'. This transformative shift brought about by the affordances of digital technology and the activity of the crowds in the cloud is best illustrated by the rise of collaborative practices like fansubbing and fandubbing, fuelled by the availability of cheap and free applications for working with multimedia and subtitling software. Usually less dogmatic and more creative than their commercial counterparts, the underlying philosophy of these practices is the sharing amongst their unofficial networks of audiovisual programmes which have been dubbed and subtitled by fans for fans (Díaz-Cintas and Muñoz-Sánchez, 2006). Although the early fansubbers started operating in the niche genre of Japanese anime, their reach has broadened substantially and, nowadays, these close-knit Internet communities with shared affinities engage in the subtitling of most audiovisual genres and languages. For scholars like Dwyer (2017), these new sites of cultural production hold much potential for democratising access to screen media and providing audiences with a voice as well as means of intervention and participation. Already, fansubbing and crowdsubtitling are being deployed as tools for literacy, education and language preservation. These newfangled collaborative practices raise numerous questions, not least from an ethical perspective, that have already attracted the attention of scholars like Pérez-González (2014) and Massidda (2015) and will no doubt continue to dominate the audiovisual landscape in the years to come.

A more contemporary, novel way of appropriating AVT for political causes has been initiated by networks of activists who make use of interventionist forms of mediation like subtitling, and to a lesser extent dubbing, to enact their own political sensitivities and structure their resistance movements. In a paradoxical way, translation is a tool used by the audiovisual media industry, which relies on professional translators, to reach and influence global audiences, whilst at the same time also exploited, in the form of subtitling and dubbing, by groups of activists that challenge and resist the established world order and try to undermine existing structures of power. These activist communities of translators and interpreters have become the recurrent object of scholarly inquiry in the wider field of translation and interpreting. Yet, their activity in AVT is less well documented although is clearly gaining 
This is the Accepted Manuscript of the article:

Díaz-Cintas, Jorge. 2018. "Audiovisual Translation in Mercurial Mediascapes", in Meng Ji and Michael Oakes (eds) Advances in Empirical Translation Studies. Cambridge: Cambridge University Press.

www.cambridge.org/core/books/advances-in-empirical-translation-studies/3C13D7A2CD1B1F0BF80ADDF2C21C7D16

momentum and attracting the attention of scholars in film studies (Nornes, 2007; Dwyer, 2017). By focusing on the subtitling of online video, Notley, Salazar and Crosby (2013) examine the way in which these instances of what they call 'citizen translation' empower activists to address social and environmental justice issues in the South East Asia region. Pérez-González’s (2014) article explores how communities of politically committed individuals without formal training in subtitling come together on the Internet to raise their voice and oppose the socio-economic structures that sustain global capitalism. Entrenched in film studies, Dwyer (2017) also discusses resistant modes of screen translation that she knows as 'guerrilla screen translation' and, in her opinion, are helping shift language patterns and hierarchies in the distribution of AVT on the net, resisting the traditional flows from the West to the rest of the globe; an assertion that seems to be sanctioned by one of the largest streaming distributors in the world: 'Netflix says English won't be its primary viewing language for much longer' (Rodríguez, 2017, online). Despite the appealing nature of these practices, and after recognising that they raise 'a host of issues relating to the broader social and political context of subtitling and dubbing in the global era' (Dwyer, 2017, 123), the scholar goes on to bemoan that their social relevance has been little discussed and remains largely beyond the purview of academia.

The communicative possibilities of AVT have expanded beyond its prima facie role of acting as a service for viewers to facilitate the understanding of a production originally shot in another language, to embrace its potential as a tool for foreign language learning (Talaván 2010, Gambier, Caimi and Mariotti, 2015). The exploration conducted on the benefits that using subtitles or other AVT modes can have on second language education is eminently empirical in nature and has attracted the interest of bodies like the European Union, which, from 2011 to 2014, funded ClipFlair (Foreign Language Learning through Interactive Captioning and Revoicing of Clips, http://clipflair.net), a research project focused on the design and development of a cloud-based platform as well as educational material for the teaching and learning of foreign languages. In a similar vein, the more recent pluriTAV (http://citrans.uv.es/pluritav) exploits the conception of AVT as a tool for the development of multilingual competences in the foreign language classroom.

Without a shred of doubt, one of the areas prospering these days is that of reception studies. Traditionally, approaches contingent on human behaviour have been avoided in AVT as they were considered to be too complex in their implementation, costly and lengthy. In addition, technology to conduct experimental research was not easily available and researchers' expertise was lacking. Yet, there is a growing consensus these days that reception studies are crucial for the sustainability of the discipline and the buttressing of links between industry and academe. In this drive to expand our knowledge of AVT, some researchers have shifted their focus from contrastive comparisons between source and target texts to zoom in on the effects that the ensuing translations have on their viewers. In this regard, AVT is a perfect example of a research area markedly interdisciplinary and increasingly eager to resort to technology, statistical analysis and social sciences methodologies to interrogate users and scrutinise data. Reception and process have taken pole position in recent scholarly exchanges and viewers, end users, as well as translation professionals and trainees are becoming the focal point of empirical and intercultural inquiry. Researchers working in AVT are no longer content with describing a product or blindly accepting inherited principles that have survived unchallenged in the printed literature. Rather, by adhering to psychometric methodologies and making use of statistical data analysis tools, they are keen to explore the impact of AVT practices on the audience, and to investigate the cognitive effort required by professionals and translators-to-be when processing translation tasks. The research project conducted by Beuchert (2017) on the exploration of the subtitling processes, by observing in situ the working routine of a sample of professional subtitlers, is a case in point. 
This is the Accepted Manuscript of the article:

Díaz-Cintas, Jorge. 2018. "Audiovisual Translation in Mercurial Mediascapes", in Meng Ji and Michael Oakes (eds) Advances in Empirical Translation Studies. Cambridge: Cambridge University Press.

www.cambridge.org/core/books/advances-in-empirical-translation-studies/3C13D7A2CD1B1F0BF80ADDF2C21C7D16

Of particular note in this attempt to measure and understand human behaviour is the application of physiological instruments, such as eye trackers, to the experimental investigation (Perego 2012). These devices, which offer metrics about visual information by measuring eye positions and eye movement, are helping scholars in AVT to move away from speculation to the analysis of data based on the observation of subjects. In this new research ecosystem, eye tracking is used to monitor viewers' attention to the various parts of the screen, in an attempt to gain a better understanding of their cognitive processes when presented with diverse concurrent stimuli such as images, sound and written subtitles in audiovisual productions. It is also a fruitful tool to gauge the audiences' enjoyment of a given size and type of font, to find out about their preferred maximum number of lines and number of characters per line of subtitle, to observe their reaction to the use of different colours and explicative glosses in the subtitles, to test their ability to read fast subtitles, to confirm their favourite positioning of the subtitles on screen, or to check whether they are aware of text crossing over shot changes and how this may affect their reading pattern.

In addition to instruments like eye trackers, and more traditional cognitive and evaluative tools such as questionnaires, interviews, think-aloud protocols and keystroke logging, a wide array of other biometric tools are also being used to conduct multisensorial experiments, such as galvanic skin response devices, that measure participants' levels of arousal, and webcams, which allow investigators to record participants and conduct facial expression analysis that, in turn, can provide cues about respondents' basic emotions (anger, surprise, joy) and levels of engagement. The potential of electroencephalography (EEG) and electrocardiograms (ECG) is also being tested with the ultimate aim of gaining an insight into cognitive-affective processes. EEG is a neuroimaging technique that helps to assess brain activity associated with perception, cognitive behaviour, and emotional processes by foregrounding the parts of the brain that are active while participants perform a task or are exposed to certain stimulus material. By tracking heart activity, ECG monitors respondents' physical state and stress levels.

From the perspective of AVT process analysis, potential areas for research could be the study of the similarities and discrepancies that can be observed in the performance of translators with differing levels of expertise (students, professionals, amateurs), the assessment of the impact that technological resources have in the activity of the professionals (use of various subtitling programs), or the evaluation of translators' productivity and enjoyment when confronted with certain tasks (spotting vs working with templates, translating vs post-editing vs quality revising). Results yielded from this experimentation could contribute to the maturation of a largely under-developed area, such as the training of audiovisual translators, by informing trainers of future audiovisual translators about the cognitive load involved in the translation process and suggesting ways of improving their curricula. The outcomes could also help language service providers specialising in AVT to adapt their practices to new workflows, to update their in-house style guides when necessary, or to reconsider some of the traditionally accepted spatial and temporal considerations that influence the translation and reception of their audiovisual programmes.

\subsection{Conclusion}

Today, the leading modes of AVT, subtitling and dubbing, are amongst the most ubiquitous translation types encountered in everyday life. This contribution has charted some of the key developments that have punctuated the evolution of AVT and has framed some of the most topical and current trends, whilst promoting new perspectives and pointing to the potential opened up by new research initiatives. As evidenced, the multimodal dimension of the object 
This is the Accepted Manuscript of the article:

Díaz-Cintas, Jorge. 2018. "Audiovisual Translation in Mercurial Mediascapes", in Meng Ji and Michael Oakes (eds) Advances in Empirical Translation Studies. Cambridge: Cambridge University Press.

www.cambridge.org/core/books/advances-in-empirical-translation-studies/3C13D7A2CD1B1F0BF80ADDF2C21C7D16

of study and the interdisciplinary nature of the research being conducted in AVT speak of a rich and complex academic subject in the making and reflect the many crossroads and junctions it presently faces. Part of the broader discipline of translation, which straddles humanities and social sciences, and confidently situated in what is increasingly being known as 'applied humanities', AVT has traditionally shown a good synergetic balance amongst all stakeholders (lecturers, scholars, practitioners, software developers, media producers and distributors) and is now forcibly pursuing an audience-centred approach in an attempt to understand the likes and dislikes of the various audiences that consume AVT in its many forms and shapes.

Although much has been done in AVT scholarship in a relatively short time span, there is still ample scope for further advancement. No doubt, there remain some conceptual and methodological gaps in the research that has been produced, and no doubt academics need to continue conducting investigations and generating new knowledge to try and fill those gaps and gain a better understanding of the field of study. Paradoxically, its inter- and multidisciplinary spirit is not only one of its most alluring attributes, it is also one of the main hoops to be jumped through as it is becoming increasingly evident that the research questions now being put forward require investigators to be competent and well-versed in different fields and, ideally, members of cross-disciplinary teams. Promoting and responding to new links between different types of knowledge and technologies can be judged a challenging prospect, albeit one worth taking and full of promise in a field as rewarding as audiovisual translation.

\section{Acknowledgements}

This research is part of the project PluriTAV, ref. FFI2016-74853-P (2017-2019), financed by the Spanish Ministry of Economy and Competitiveness (Programa Proyectos I+D Excelencia).

\section{References}

Ávila Cabrera, José Javier (2014). The subtitling of offensive and taboo language: A descriptive study. PhD thesis. Madrid: Universidad Nacional de Educación a Distancia.

Baker, Robert G., Andrew D. Lambourne and Guy Rowston (1984). Handbook for Television Subtitlers. Winchester: Independent Broadcasting Authority.

Baldry, Anthony and Paul J. Thibault (2006). Multimodal Transcription and Text Analysis. London: Equinox.

Baños, Rocío, Silvia Bruti and Serenella Zanotti (2013). Corpus linguistics and audiovisual translation: in search of an integrated approach. Perspectives 21(4), 483-490.

Beseghi, Micòl (2017). Multilingual Films in Translation: A Sociolinguistic and Intercultural Approach. Oxford: Peter Lang.

Beuchert, Kathrine (2017). The web of subtitling: a subtitling process model based on a mixed methods study of the Danish subtitling industry and the subtitling processes of five Danish subtitlers. PhD thesis. Aarhus: Aarhus University.

Bywood, Lindsay, Panayota Georgakopoulou and Thierry Etchegoyhen (2017). Embracing the threat: Machine translation as a solution for subtitling. Perspectives 25(3), 492-508.

Chaume, Frederic (2013). The turn of audiovisual translation: New audiences and new technologies. Translation Spaces 2, 105-123.

de Higes Andino, Irene (2014). Estudio descriptivo y comparativo de la traducción de filmes plurilingües: el caso del cine británico de migración y diaspora. PhD thesis. Castellón: University Jaume I.

Delabastita, Dirk (1989). Translation and mass-communication: film and TV translation as evidence of cultural dynamics. Babel 35(4), 193-218. 
This is the Accepted Manuscript of the article:

Díaz-Cintas, Jorge. 2018. "Audiovisual Translation in Mercurial Mediascapes", in Meng Ji and Michael Oakes (eds) Advances in Empirical Translation Studies. Cambridge: Cambridge University Press.

www.cambridge.org/core/books/advances-in-empirical-translation-studies/3C13D7A2CD1B1F0BF80ADDF2C21C7D16

de Linde, Zoe and Neil Kay (1999). The Semiotics of Subtitling. Manchester: St. Jerome.

Díaz-Cintas, Jorge (2012). Clearing the smoke to see the screen: Ideological manipulation in audiovisual translation. Meta 57(2), 279-293.

Díaz-Cintas, Jorge (2019). Film censorship in Franco's Spain: the transforming power of dubbing. Perspectives: Studies in Translation Theory and Practice 27(2), 182-200.

Díaz-Cintas, Jorge and Aline Remael (2007). Audiovisual Translation: Subtitling. London: Routledge.

Díaz-Cintas, Jorge and Pablo Muñoz Sánchez (2006). Fansubs: Audiovisual translation in an amateur environment. The Journal of Specialised Translation 6: 37-52.

Dwyer, Tessa (2017). Speaking in Subtitles: Revaluing Screen Translation. Edinburgh: Edinburgh University Press.

Elks, Sonia (2012). Children 'spend one year in front of screens by the age of seven'. Metro, 21 May. http://metro.co.uk/2012/05/21/children-spend-one-year-in-front-of-screens-bythe-age-of-seven-433743

Estopace, Eden (2017). Audiovisual translation hits a sweet spot as subscription video ondemand skyrockets. Slator, Language Industry Intelligence, 23 November.

https://slator.com/features/audiovisual-translation-hits-sweet-spot-subscription-videoon-demand-skyrockets

Ferri, Paolo (2012). Digital and inter-generational divide. In Antonio Cartelli, ed., Current Trends and Future Practices for Digital Literacy and Competence. Hershey PA: IGI Global, 1-18.

Freddi, Maria and Maria Pavesi, eds, (2009). Analysing Audiovisual Dialogue: Linguistic and Translational Insights. Bologna: Clueb.

Fryer, Louise (2016). Introduction to Audio Description: A Practical Guide. London: Routledge.

Gambier, Yves, Annamaria Caimi and Cristina Mariotti, eds, (2015). Subtitles and Language Learning: Principles, Strategies and Practical Experiences, Bern: Peter Lang.

Gambier, Yves and Sara Ramos Pinto (2016). Introduction. Target 28(2), 185-191.

Gutiérrez Lanza, Camino (2002). Spanish film translation and cultural patronage: the filtering and manipulation of imported material during Franco's dictatorship. In Maria Tymoczko and Edwin Genzler, eds, Translation and Power. Massachusetts: University of Massachusetts, 141-159.

Jenkins, Henry (2006). Convergence Culture: Where Old and New Media Collide. New York: New York University Press.

Jumpelt, Rudolf Walter (1961). Die Übersetzen naturwissenschaftlicher und technischer Literatur: sprachliche Maßstäbe und Methoden zur Bestimmung ihrer Wesenszüge und Probleme. Berlin: Langenscheidt.

Kayahara, Matthew (2005). The digital revolution: DVD technology and the possibilities for audiovisual translation studies. The Journal of Specialised Translation 3, 64-74.

Lefevere, André (1992). Translation, Rewriting and the Manipulation of Literary Fame. London: Routledge.

Leung, Dawning (2015). Audio description in Hong Kong. In Rocío Baños Piñero and Jorge Díaz-Cintas, eds, Audiovisual Translation in a Global Context. Mapping and Everchanging Landscape. Basingstoke: Palgrave Macmillan, 266-281.

Martínez-Sierra, Juan José (2008). Humor y traducción: Los Simpson cruzan la frontera. Castellón: Universitat Jaume I.

Massidda, Serenella (2015). Audiovisual Translation in the Digital Age: The Italian Fansubbing Phenomenon. Basingstoke: Palgrave Macmillan.

Maszerowska, Anna, Anna Matamala and Pilar Orero, eds, (2014). Audio Description - New 
This is the Accepted Manuscript of the article:

Díaz-Cintas, Jorge. 2018. "Audiovisual Translation in Mercurial Mediascapes", in Meng Ji and Michael Oakes (eds) Advances in Empirical Translation Studies. Cambridge: Cambridge University Press.

www.cambridge.org/core/books/advances-in-empirical-translation-studies/3C13D7A2CD1B1F0BF80ADDF2C21C7D16

Perspectives Illustrated. Amsterdam: John Benjamins.

Mereu Keating, Carla (2016). The Politics of Dubbing. Film Censorship and State Intervention in the Translation of Foreign Cinema in Fascist Italy. Oxford: Peter Lang.

MESA News (2017). Study: EMEA content localization service spending hits $\$ 2$ billion. Media \& Entertainment Services Alliance, 27 June.

www.mesalliance.org/2017/06/27/study-emea-content-localization-service-spendinghits-2-billion

Neves, Josélia (2005). Subtitling for the Deaf and Hard of Hearing. PhD thesis. London: Roehampton University.

Nornes, Abé Mark (2007). Cinema Babel: Translating Global Cinema. Minneapolis: University of Minnesota Press.

Notley, Tanya, Juan Francisco Salazar and Alexandra Crosby (2013). Online video translation and subtitling: examining emerging practices and their implications for media activism in South East Asia. Global Media Journal - Australian Edition 7(1), 1-15.

http://researchdirect.westernsydney.edu.au/islandora/object/uws\%3A17810/datastream /PDF/view

O'Sullivan, Carol (2013). Introduction: Multimodality as challenge and resource for translation. The Journal of Specialised Translation 20, 2-14.

Pedersen, Jan (2011). Subtitling Norms for Television: An Exploration Focussing on Extralinguistic Cultural References. Amsterdam: John Benjamins.

Perego, Elisa, ed., (2012). Eye Tracking in Audiovisual Translation. Roma: Aracne.

Pérez-González, Luis (2014). Audiovisual Translation: Theories, Methods and Issues. London: Routledge.

Prensky, Marc (2001). Digital natives, digital immigrants part 1. On the Horizon 9(5), 1-6.

Pruys, Guido Marc (1997). Die Rhetorik der Filmsynchronisation. Wie ausländische Spielfilme in Deustschland zensiert, verändert und gesehen werden. Tübingen: Gunter Narr.

Ramière, Nathalie (2007). Strategies of cultural transfer in subtitling and dubbing. PhD thesis. Brisbane: University of Queensland.

Ranzato, Irene (2016). Translating Culture Specific References on Television: The Case of Dubbing. London: Routledge.

Reiss, Katharina (1981). Type, kind and individuality of text: Decision making in translation. Poetics Today 2(4), 121-131.

Reiss, Katharina (2000/1971). Translation Criticism - The Potentials and Limitations: Categories and Criteria for Translation Quality Assessment. Translated by Erroll F. Rhodes. Manchester and New York: St Jerome and American Bible Society.

Reuters (2015). YouTube introduces new translation tools to globalise content. ET Brand Equity, 21 November.

https://brandequity.economictimes.indiatimes.com/news/digital/youtube-introducesnew-translation-tools-to-globalize-content/49860574

Rodríguez, Ashley (2017). Netflix says English won’t be its primary viewing language for much longer. Quartz, 30 March.

https://qz.com/946017/netflix-nflx-says-english-wont-be-its-primary-viewing-

language-for-much-longer-unveiling-a-new-hermes-translator-test

Romero-Fresco, Pablo (2011). Subtitling through Speech Recognition: Respeaking. London: Routledge.

Romero-Fresco, Pablo (2013). Accessible filmmaking: Joining the dots between audiovisual translation, accessibility and filmmaking. The Journal of Specialised Translation 20, 201-223.

Schwab, Klaus (2016). The Fourth Industrial Revolution. Geneva: World Economic Forum. 
This is the Accepted Manuscript of the article:

Díaz-Cintas, Jorge. 2018. "Audiovisual Translation in Mercurial Mediascapes", in Meng Ji and Michael Oakes (eds) Advances in Empirical Translation Studies. Cambridge: Cambridge University Press.

www.cambridge.org/core/books/advances-in-empirical-translation-studies/3C13D7A2CD1B1F0BF80ADDF2C21C7D16

Shetty, Amit (2016). VAST 4.0 arrives, championing the technology behind the growth of digital video advertising. iab, 21 January. www.iab.com/news/vast-4-0-arriveschampioning-thetechnology-behind-the-growth-of-digital-video-advertising

Snell-Hornby, Mary (2006). The Turns of Translation Studies. New Paradigms or Shifting Viewpoints? Amsterdam: John Benjamins.

Talaván, Noa (2010). Subtitling as a task and subtitles as support: Pedagogical applications. In Jorge Díaz-Cintas, Anna Matamala and Josélia Neves, eds, New Insights into Audiovisual Translation and Media Accessibility. Amsterdam: Rodopi, 285-299.

Tamayo-Masero, Ana (2015). Estudio descriptivo y experimental de la subtitulación en TV para niños sordos: una propuesta alternativa. PhD thesis. Castellón: Universitat Jaume I.

Toury, Gideon (1995). Descriptive Translation Studies - and Beyond. Amsterdam: John Benjamins.

Vandaele, Jerome (2002). Funny fictions: Francoist translation censorship of two Billy Wilder films. The Translator 8(2), 267-302.

Vercauteren, Gert (2016). A narratological approach to content selection in audio description. $\mathrm{PhD}$ thesis. Antwerp: University of Antwerp.

Weaver, Sarah (2014). Lifting the curtain on opera translation and accessibility: Translating opera for audiences with varying sensory ability. PhD thesis. Durham: Durham University.

Yuan, Long (2016). The subtitling of sexual taboo from English into Chinese. PhD thesis. London: Imperial College.

Zabalbeascoa, Patrick (1996). Translating jokes for dubbed television situation comedies. The Translator 2(2), 235-57.

Zárate, Soledad (2014). Subtitling for deaf children: Granting accessibility to audiovisual programmes in an educational way. PhD thesis. London: University College London. 